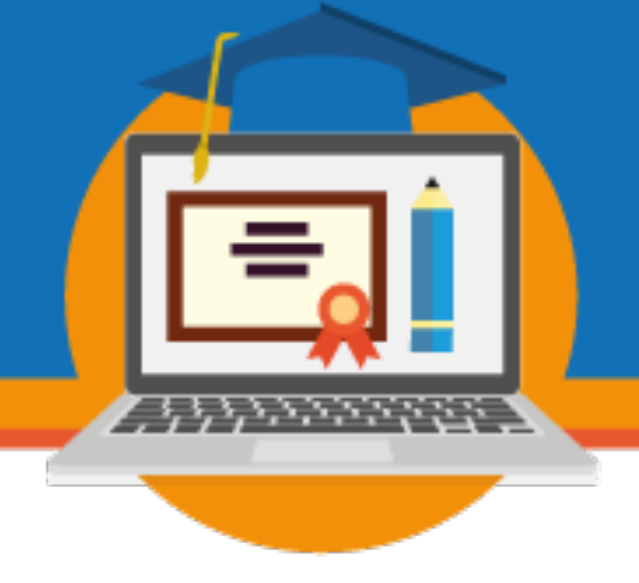

\title{
ESTRUTURA E ORGANIZAÇÕES DA EAD NO CENÁRIO DE INSTITUIÇÕES DO CENTRO-OESTE
}

\author{
Mirtes Dâmares Santos de Almeida Maia \\ Universidade Federal de Mato Grosso, bolsista CAPES \\ mirtes.almeidam@gmail.com \\ Rogéria Rosária Parra Merino de Macêdo \\ Universidade Federal de Mato Grosso \\ rogeria_merino@hotmail.com
}

Eixo 1 - Política, gestão e financiamento da educação a distância

Resumo: Considerando o cenário de instituições da região Centro-oeste, o presente trabalho tem por objetivo proporcionar uma reflexão sobre a expansão de ofertas de vagas na $\mathrm{EaD}$ em IES públicas e privadas, no período de 2014 a 2019. É uma análise documental de dados estatísticos obtidos em documentos formais sobre o ensino superior e, em específico, a análise de relatórios parciais da pesquisa intitulada "Políticas de Expansão da Educação a Distância (EaD) no Brasil: Regulação, Qualidade e Inovação em Questão", aprovada pela Chamada MCTIC/CNPq Universal n. 28/2018 e desenvolvida entre 2019 e 2021 na região Centro-Oeste. A análise dos relatórios aponta semelhanças quanto às estruturas da $\mathrm{EaD}$ nas IES, porém, um avanço tímido no que se refere a questões de expansão de cursos a distância.

Palavras-chave: EaD. Expansão. Organização.

\section{Introdução}

A expansão da $\mathrm{EaD}$ no Brasil é uma realidade consubstancial e complexa, já que, os dados obtidos a partir de levantamentos estatísticos, de pesquisas na área, estudos sobre a temática remetem a um panorama com índices claros e objetivos sobre a evolução de oferta de vagas. Ressalta-se que dar acesso envolve bem mais que possibilitar o ingressar no ensino superior, já que, para que o saber seja construído e esta etapa concluída, necessário se faz ter acesso, permanência e aprendizagem, e considerar estas dimensões remete as espaços significativos para pensar em como se dá a dinâmica e o processo de expansão da EaD no 
cenário das instituições públicas e privadas no cenário nacional e, em especial na Região Centro-Oeste.

Neste contexto, o texto que segue tem como objetivo proporcionar uma reflexão sobre a expansão de oferta de vagas na $\mathrm{EaD}$ em IES públicas e privadas da região Centro-oeste, no período de 2014 a 2019. O trabalho tem como arcabouço metodológico a análise documental, cujo foco volta-se a dados estatísticos obtidos em documentos formais sobre o Ensino Superior e, em específico, a análise dos relatórios parciais da pesquisa intitulada "Políticas de Expansão da Educação a Distância (EaD) no Brasil: Regulação, Qualidade e Inovação em Questão", aprovada pela Chamada MCTIC/CNPq Universal n. 28/2018 e desenvolvida entre 2019 e 2021, na região Centro-Oeste.

Os relatórios se apresentam como resultado de um processo colaborativo envolvendo diversos atores e instituições. A pesquisa objetiva analisar as concepções, dimensões, mecanismos de qualidade e inovação presentes na oferta e expansão da educação a distância, considerando suas mudanças de trajetória, regulamentação, presença e estratégias de atuação de atores, que atuam e lidam com a modalidade. Para seu desenvolver, foi realizada revisão de literaturas que tratam das temáticas $\mathrm{EaD}$, qualidade e inovação, com o propósito de construir um arcabouço teórico que busque compreender esses conceitos numa perspectiva de desenvolvimento social e como subsídio para a elaboração dos instrumentos de coleta de dados nas instituições participantes da pesquisa.

Assim, o presente artigo tem como proposta compreender a dinâmica que envolve o processo de expansão de vagas em EaD, especialmente na região Centro-Oeste. Ressalta-se que as vertentes pública e privada são os elementos da analogia que alimentam a reflexão proposta.

Neste contexto, este texto propõe debater e refletir sobre a EaD a partir das nuances da expansão de vagas em IES públicas e privadas do Centro-oeste, em busca de compreender o percurso realizado em relação a oferta e estruturação desta modalidade em onze' instituições participantes da pesquisa em andamento anteriormente citada.

${ }^{1}$ Universidade Federal de Goiás (coord. Daniela Lima); Universidade de Brasília (Coord. Catarina Almeida e Danielle Xabregas); Universidade Federal de Mato Grosso (Coord. Kátia Alonso e Cristiano Maciel);

Universidade Federal de Mato Grosso do Sul (Coord. Carina Maciel e Daiani Riedner); Universidade Federal da

\section{SEMINÁRIO DE EDUCAÇÃO A DISTÂNCIA}




\section{$\equiv$

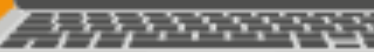 \\ i}

\section{EaD: as nuances históricas e legais}

O processo histórico da $\mathrm{EaD}$ no cenário nacional se dá em três momentos distintos. No entanto, segundo Mill (2018), o que caracteriza e embasa atualmente o cenário da educação a distância é a integração tecnológica quase que total, possibilitando aos alunos a utilização dos mais diversos recursos de Tecnologias de Informação e Comunicação (TIC).

A compreensão de que $\mathrm{EaD}$ está além do manusear os artefatos para promover o aprender, perpassa o exercício de pensar a estruturação e organização desta como um todo. Neste contexto, torna-se essencial para a ruptura de pré-conceitos e estereótipos a compreensão de que para possibilitar acesso, permanência e qualidade no aprender, as políticas públicas devem envolver a estruturação, organização e institucionalização da Educação, preconizando os saberes, a inserção social e a sensibilidade crítica e libertadora.

Esta perspectiva de pensar Educação em um movimento crítico e, que ultrapasse a visão de estratificar a EaD em modalidade pode ser compreendida nas palavras de Alonso (2010):

É relevante destacar que o problema da formação em nível superior e a consequente expansão desse nível de ensino indicam movimento que, independe da modalidade em que se processa a formação superior: se presencial ou não presencial, define a lógica que a conforma. É essa dinâmica que implica e redunda os atuais modelos de EaD em nosso país. (...) Se, com relação ao movimento mais amplo da expansão do ensino superior, a natureza das instituições supõe organizações diversas para a oferta de cursos com marcações específicas segundo seu status se universidades ou não no caso da EaD, e, considerando a documentação relacionada à sua institucionalização, percebe-se, claramente, proposição de sistema que equaciona a oferta de vagas fundamentada em determinados elementos que independem da natureza jurídica e/ou institucional dos estabelecimentos de ensino superior (ALONSO, 2010, p. 1321)

As proposições de entender $\mathrm{EaD}$ e seu contexto histórico permeia compreender a educação de forma holística, desde suas forças/fraquezas, fragilidades/fortalezas, conquistas/perdas, avanços/retrocessos etc. Porém, o que se observa, no cenário nacional e na

Grande Dourados (Coord. Giselle Real); Universidade Católica Dom Bosco (Coord. Maria Cristina Paniago); Pontifícia Universidade Católica de Goiás (Coord. Rose Almas); Instituto Federal de Goiás (Coord. Rosselini Ribeiro); Instituto Federal Goiano (Coord. Joseany Cruz); Instituto Federal de Brasília (Coord. Rute Bicalho); Universidade Estadual de Goiás (Coord. Gisele Bernardes).

\section{SEMINÁRIO DE EDUCAÇÃO A DISTÂNCIA}




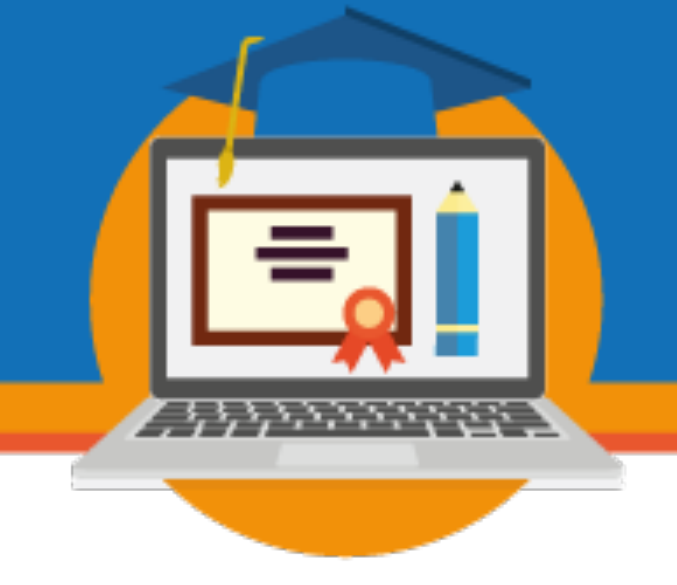

análise documental realizada é uma constante necessidade de expansão de vagas que tem se alicerçado na oferta sem os devidos cuidados que essa oferta de Educação de Qualidade requer.

Em relação à trajetória da regulamentação da $\mathrm{EaD}$ no cenário nacional, observa-se como ponto central a aprovação da Lei de Diretrizes e Bases da Educação Nacional-LDB $\mathrm{n}^{\circ}$ 9.394/1996, que abre possibilidade explícita, mas não legalmente resolvida, sobre a oferta em $\mathrm{EaD}$.

Após, vieram os primeiros instrumentos reguladores: Decreto $\mathrm{n}^{\circ} 2.494 / 1998$, alterado pelo Decreto $n^{\circ} 2.561 / 1998$ e Portaria Ministerial $n^{\circ} 301 / 1998$, revogada pela Portaria $n^{\circ}$ 4.361/2004. Aqui foram detalhados os procedimentos, etapas e necessidades para o processo de solicitação de credenciamento de cursos superiores, incluindo a EaD. Na pós-graduação lato sensu, o Conselho Nacional de Educação (CNE) estabelece a Resolução CNE/CES nº 01/2001, que regulamenta suas atividades a distância. Com as limitações dos primeiros decretos, surge o Decreto $n^{\circ} 5.622 / 2005$, alterado pelo Decreto $n^{\circ} 6.303 / 2007$, que revoga os anteriores. Este permite a EaD na pós-graduação stricto sensu, porém, aponta para a necessidade de instrumento jurídico específico. Este decreto reforça ainda a necessidade de se atentar para os Referenciais da Qualidade para Educação Superior a Distância, publicado em 2007.

Ao olhar o contexto legal, percebe-se que somente após dez anos de aprovação da LDB foi criado um projeto público, denominado Sistema Universidade Aberta do Brasil (UAB), instituído pelo Decreto $\mathrm{n}^{\circ} 5.800 / 2006$, o qual tem servido de financiador na oferta de cursos em EaD nas IES públicas.

A legitimações citadas são tidas como base para a maioria das instituições participantes da pesquisa, porém o processo interno de estruturação e organização das IES analisadas tem suas especificidades.

\section{Dinâmica e processo de expansão de vagas em EaD}

Segundo dados oficiais do Censo do Ensino Superior 2018 e dos relatórios, o avanço da EaD se comprovou de forma expressiva. Pela primeira vez, segundo dados do MEC/Inep 2018, 
o número de vagas na modalidade EaD superou as presenciais. No entanto, apesar da maior oferta ser em EaD em 2018, o número de ingressantes e matriculados em cursos presenciais ainda é superior, o que pode ser visto no Quadro 1.

\section{Quadro 1}

\begin{tabular}{|c|c|c|}
\hline \multicolumn{3}{|c|}{ Ingressantes e Matriculados no Ensino Superior } \\
\hline Alunos & Presencial & $\mathrm{EaD}$ \\
\hline Ingressantes & 2.072 .614 & 1.373 .321 \\
\hline Matriculados & 6.394 .244 & 2.056 .511 \\
\hline
\end{tabular}

Fonte: MEC/Inep; Censo da Educação Superior 2018.

A partir dos dados do Quadro 1, é possível abrir espaço para questionamentos relacionados às razões para essa não correspondência de expectativa.

Outro fator questionável pode ser visto no Quadro 2, relacionado ao aumento expressivo de vagas e matrículas em IES privadas, passando à frente das instituições públicas que, segundo outros dados, têm sofrido uma diminuição na oferta de cursos, inclusive no Centro-oeste.

Quadro 2

\begin{tabular}{|c|c|c|c|c|c|c|c|c|}
\hline \multirow[b]{2}{*}{$\begin{array}{l}\text { Unidade da } \\
\text { Federação / } \\
\text { Categoria } \\
\text { Administrati } \\
\text { va }\end{array}$} & \multirow{2}{*}{$\begin{array}{l}\mathrm{N}^{\circ} \text { de } \\
\text { Polo }\end{array}$} & \multicolumn{5}{|c|}{ Ingressos } & \multirow[b]{2}{*}{ Matrículas } & \multirow[b]{2}{*}{$\begin{array}{l}\text { Concluinte } \\
\text { s }\end{array}$} \\
\hline & & Totais & $\begin{array}{l}\text { Seleção } \\
\text { para } \\
\text { Vagas } \\
\text { Novas }\end{array}$ & $\begin{array}{l}\text { Seleção } \\
\text { para } \\
\text { vagas de } \\
\text { program } \\
\text { as } \\
\text { especiai } \\
\text { s }\end{array}$ & $\begin{array}{l}\text { Seleção para } \\
\text { Vagas } \\
\text { Remanescen } \\
\text { tes }\end{array}$ & $\begin{array}{l}\text { Ingresso } \\
\mathrm{s} \quad \text { por } \\
\text { Outras } \\
\text { Formas }\end{array}$ & & \\
\hline Brasil & 12.112 & $\begin{array}{c}1.373 .32 \\
1\end{array}$ & $\begin{array}{c}1.236 .16 \\
3\end{array}$ & 4.182 & 132.690 & 286 & 2.056 .511 & 273.873 \\
\hline Pública & 1.802 & 62.643 & 60.382 & 444 & 1.774 & 43 & 172.927 & 16.852 \\
\hline Fed. & 941 & 22.105 & 20.830 & 444 & 795 & 36 & 93.075 & 11.045 \\
\hline Est. & 837 & 39.497 & 38.765 & -- & 725 & 7 & 77.949 & 5.542 \\
\hline Mun & 24 & 1.041 & 787 & -- & 254 & -- & 1.903 & 265 \\
\hline Privada & 10.310 & $\begin{array}{c}1.310 .67 \\
8\end{array}$ & $\begin{array}{c}1.175 .78 \\
1\end{array}$ & 3.738 & 130.916 & 243 & 1.883 .584 & 257.021 \\
\hline $\begin{array}{l}\text { Centro } \\
\text { Oeste }\end{array}$ & 1.152 & 130.399 & 119.731 & 167 & 10.493 & 8 & 183.438 & 26.096 \\
\hline
\end{tabular}




\begin{tabular}{|l|l|c|c|c|c|c|c|c|c|}
\hline \multicolumn{2}{|l|}{ Pública } & 112 & 1.893 & 1.410 & -- & 478 & 5 & 8.686 & 1.227 \\
\hline \multicolumn{2}{|c|}{ Fed. } & 68 & 622 & -- & -- & 135 & 1 & 5.576 & 659 \\
\cline { 2 - 10 } & Est. & 44 & 1.271 & -- & -- & 343 & 4 & 3.110 & 568 \\
\cline { 2 - 10 } & Mun & -- & -- & -- & -- & -- & -- & - \\
\hline \multicolumn{2}{l}{ Privada } & 1.040 & 128.506 & 118.321 & 167 & 10.015 & 3 & 174.752 & 24.869 \\
\hline
\end{tabular}

Fonte: Dados obtidos em Sinopse da Educação Superior 2018

\section{Dinâmica da organização da EaD nas instituições do Centro-oeste e suas características}

A partir daí, e com base nos relatórios, passa-se às questões relacionadas à organização e expansão da $\mathrm{EaD}$ nas instituições no centro-oeste, destacando as principais características e semelhanças. As instituições participantes são: Universidade Estadual de Goiás (UEG); Universidade Federal de Goiás (UFG); Universidade Federal de Mato Grosso (UFMT); Universidade Federal de Mato Grosso do Sul (UFMS); Universidade Federal da Grande Dourados (UFGD); Universidade de Brasília (UnB); Instituto Federal Goiano (IF Goiano); Instituto Federal de Goiás (IFG); Instituto Federal de Brasília (IFB); Universidade Católica Dom Bosco (UCDB); e PUC Goiás.

Segundo relatórios, os documentos institucionais reguladores, de maneira geral, são os Regimentos Gerais, os Estatutos, os Projetos Políticos Institucionais (PPI), os Projetos de Desenvolvimento Institucional (PDI), entre outros, que, de alguma forma tratam da EaD. Nem todos eles contemplam a EaD para todas as instituições, mas, os PPI e os PDI, trazem pontuações sobre a $\mathrm{EaD}$ e oferta de disciplinas a distância na maioria das instituições.

Interessante frisar que o PDI da UFG considerou a EaD como modalidade que utiliza as Tecnologias da Informação e Comunicação na mediação didático-pedagógica nos processos de ensino e aprendizagem, e coloca o ensino presencial, o semipresencial e a EaD em função igualitária. Em relação a datas, grande parte dos relatórios mostrou referência a EaD desde antes de 2009.

Embora tais documentos regulatórios sejam diferentes, parte dos relatórios trouxe convergência quanto ao objetivo da $\mathrm{EaD}$, caracterizando-a como modalidade educacional utilizada como estratégia de expansão e democratização ao acesso à educação. Em alguns, os 


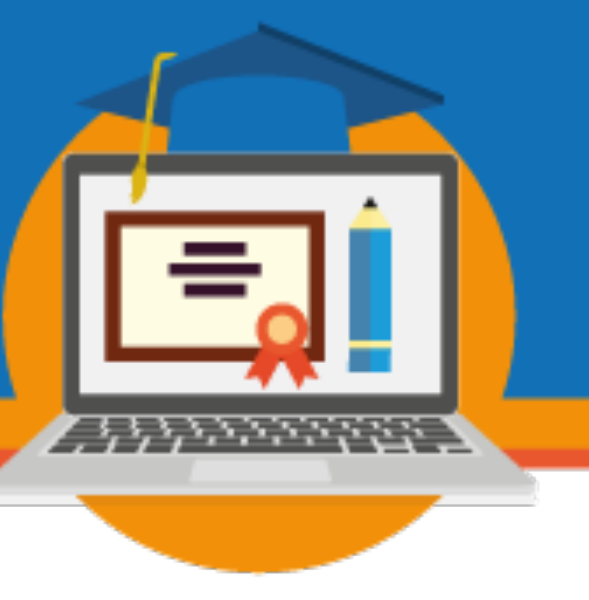

documentos pontuam claros objetivos visando à manutenção da qualidade e níveis elevados nas práticas e resultados da educação. Segundo outros, a EaD é concebida como possibilitadora de inovação.

Quanto à trajetória organizacional e de expansão, a UFMT e a UnB aclamam reconhecimento pelo pioneirismo no que tange às iniciativas da $\mathrm{EaD}$ no ensino superior no Brasil. No entanto, é-nos detalhadamente relatado que a UFMT, no período de 1995 a 2005, por meio do Núcleo de Educação Aberta e a Distância do Instituto de Educação, idealizou e implementou o primeiro curso de licenciatura a distância aprovado pelo Ministério da Educação. Em 2006, a UFMT aderiu ao Sistema Universidade Aberta do Brasil (UAB), o que foi um marco, pois culminou na expansão interna na oferta de cursos de graduação e especialização para outras unidades acadêmicas.

Temos então a estruturação da modalidade, respeitando a estrutura acadêmicoadministrativa da UFMT, cujas unidades acadêmicas (Institutos e Faculdades) são consideradas órgãos executivos com atribuições de planejar, executar e avaliar as atividades de ensino, pesquisa e extensão. Segundo o relatório da instituição, "mininúcleos" de EaD foram organizados nas UA ofertantes de cursos de graduação, mas coube à UAB fazer a coordenação geral do programa e oferecer a orientação pedagógica, administrativa e suporte financeiro aos cursos. De 2007 a 2016 a EaD na UFMT esteve organizada de modo descentralizado, já que não havia órgão institucional próprio para gerir a modalidade.

Atualmente, a EaD na UFMT se encontra na Secretaria de Tecnologia Educacional (SETEC), órgão vinculado à reitoria, que ampliou o leque de ações direcionadas à educação mediada por tecnologias, com a proposta de viabilizar cursos a distância por meio de Recursos Educacionais Abertos e híbridos.

Já a UnB, em 2006, tendo aderido à Universidade Aberta do Brasil (UAB), ofertou um curso piloto de graduação e, em 2007, passou a ofertar cursos de licenciaturas e especialização na área de formação docente. De acordo com o relatório, de 2006 a 2017, a UnB esteve presente em trinta e sete municípios alocados entre as cinco regiões do país, com oferta de 9.527 vagas. No entanto, entre 2018 e 2019, a instituição não recebeu novos alunos. 
Pelos relatórios, temos outras instituições que iniciaram a oferta de EaD por cursos de graduação, a exemplo da UFGD, que ofertou um, em 2009, por meio de convênio com a Universidade Federal de Santa Catarina. Posteriormente, a EaD ganhou espaço após a adesão ao Sistema UAB. Com esse apoio, a UFGD começa a estruturar um corpo docente para o desenvolvimento dos primeiros cursos a distância. Inicialmente, três cursos foram implementados em 2012 e em 2014 mais dois foram acrescentados. Além do financiamento da UAB, a instituição contou com apoio do "Plano Nacional dos Direitos da Pessoa com Deficiência - Programa Viver sem Limites" na oferta da Licenciatura em Libras, curso institucionalizado na UFGD (VILELA, 2019). Nos anos seguintes, entre 2013 e 2015, houve uma expansão na oferta de cursos a distância, mas desta vez contemplando quatro áreas de especialização, o que fez com que a EaD ganhasse mais espaço em contexto educacional.

Em 2014, após a publicação do PDTI, a EaD foi elevada ao nível de Faculdade, assemelhando-se às demais estruturas que agregam os cursos presenciais na UFGD. Com essa mudança, cresceu-se a expectativa em relação à expansão da EaD na instituição, mas, segundo o relatório, é perceptível uma queda no número de alunos matriculados. Acredita-se que tal fenômeno foi causado pela diminuição da oferta de cursos pelo sistema UAB, que deixou de apresentar regularidade nos Editais para abertura de novos cursos e turmas.

Percebeu-se também que outra parte das IE públicas iniciaram a EaD com a oferta de cursos que não de graduação, a exemplo da UEG que, desde 2000, oferecia cursos com o objetivo de dar suporte às unidades universitárias em projetos de EaD. No entanto, foi em 2004, depois do lançamento de edital dirigido aos docentes da instituição para receber propostas de cursos a distância, que a UEG obteve o marco piloto na história da $\mathrm{EaD}$, com o curso de Contadores de História.

As próximas ofertas da UEG foram realizadas por meio de parcerias com outras instituições de ensino superior via consórcios. Tais associações impulsionaram oferta de cursos de graduação em licenciatura e, em 2005, a UEG participou da oferta de dois cursos de licenciatura (STACHEIRA et al, 2015). Em 2006, ela aderiu à UAB e expandiu as ofertas. Atualmente, a UEG tem o Centro de Ensino e Aprendizagem em Rede (CEAR), como o 
responsável pela modalidade e oferece cursos de graduação, pós-graduação, extensão e capacitação, além de disciplinas a distância em cursos presenciais. Apesar de expectativas de crescimento, o relatório aponta para falta de organicidade da modalidade dentro da instituição. Além disso, visto que a $\mathrm{EaD}$ ainda não se encontra institucionalizada na IES e o financiamento se dá pela CAPES-UAB, é comum falta de regularidade de oferta de cursos.

Na UFMS, a EaD iniciou em 1991, informalmente, por meio do Grupo de Apoio ao Ensino de Ciências e Matemática no $1^{\circ}$ Grau. Composto por professores, o grupo tinha por objetivo criar um organismo interdisciplinar de oferta de cursos a distância para qualificação dos professores da rede pública. Posteriormente, no fim da década de 1990, foram feitas as primeiras implantações de cursos de extensão e de especialização no âmbito da Assessoria de Educação Aberta e a Distância (AEAD), em plataformas virtuais (BATISTA; GOBARA, 2006). Mas foi em 2000 que se oficializou a criação, implantação, divulgação e regimento interno da AEAD na UFMS.

Em 2008, a UFMS ofertou cursos de graduação e pós-graduação a distância pela UAB. Entretanto, cabe pontuar que o relatório dessa instituição aponta para uma limitação provinda da UAB em relação aos municípios de atuação e às ofertas de cursos, o que restringe a expansão da EaD.

Da UFG, tem-se descrito seu início formal em 2000, mas, só em 2007 surgiu o Centro Integrado de Aprendizagem em Rede (CIAR), órgão suplementar vinculado a Reitoria que tinha como finalidade implementar e apoiar as atividades acadêmicas de graduação, pós-graduação, extensão e pesquisa integradas pelas Tecnologias Digitais da Informação e Comunicação e na modalidade a distância. Segundo o relatório, o CIAR tem papel fundamental no processo de viabilização, dinamização, expansão e difusão de projetos de EaD no âmbito institucional junto à $\mathrm{UAB}$, que financia a maioria dos cursos na UFG.

Em relação aos IF, pode-se dizer que as implantações da EaD iniciaram de forma tímida recentemente, quando em comparação com outras instituições. Os institutos também compartilharam da situação de financiamento por meio da Rede e-Tec Brasil para a oferta de cursos técnicos subsequentes ao Ensino Médio, entre outros, antes de se vincularem à UAB 


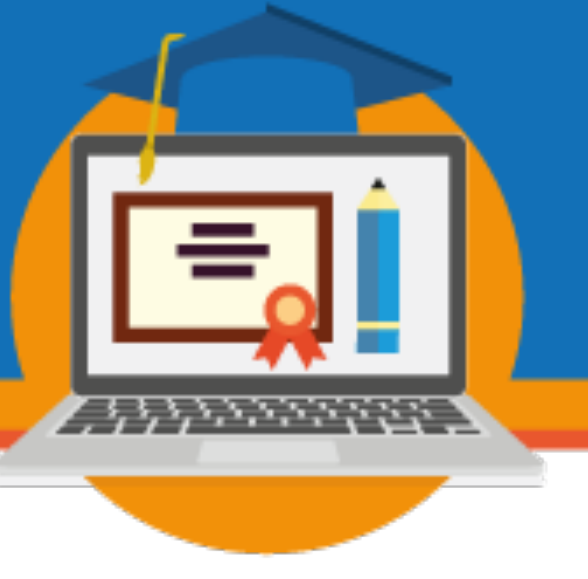

para a oferta de cursos superiores a distância em nível de graduação e especialização. Após esse vínculo é apontada nos relatórios pouca oferta de cursos, descontinuidade ou suspensão de ofertas, causadas pela falta de um financiamento para institucionalização.

Quanto às instituições privadas, a PUC Goiás iniciou a EaD em 1997 com o Programa de Graduação Itinerante, que culminou no Centro de Educação Aberta e a Distância (CEAD). Em 2003, o CEAD passou a se chamar "Coordenação de Educação a Distância (Cead)", recebendo grande responsabilidade na gestão acadêmica-administrativa.

Em 2007, a instituição recebeu credenciamento institucional, um marco para a consolidação da EaD. No período de 2006 a 2014 foram oferecidos mais cursos (graduação e especialização), os quais alcançaram número considerável de formandos. Em 2017 ela recebe novo credenciamento e é traçada uma Política de Ensino em EaD com base no PDI e no PPI. São iniciadas ações para a institucionalização da EaD e, em 2019, são consolidadas ofertas de diversos cursos de ensino superior.

A UCDB recebeu credenciamento em 2005, por meio de convênios firmados com a Missão Salesiana em todo Brasil. Em 2008, ela ofereceu vários cursos tecnológicos e em 2015 três cursos de licenciatura. O relatório justifica que os cursos em $\mathrm{EaD}$ ainda estão se desenvolvendo e se ajustando na instituição e têm o incentivo de investimentos.

Embora os dados coletados no Censo apontem para uma expansão da EaD no setor privado, não obtivemos dados, desses relatórios, que isso confirmassem, visto que a PUC Goiás ofereceu cursos em momentos pontuais e atendendo a demandas específicas e, de 2015 a 2019 não ofertou cursos de graduação e especialização. A UCDB apresentou no relatório um leve decréscimo no número de matrículas.

\section{Considerações Finais}

De forma geral percebe-se, nas instituições públicas analisadas, um movimento para a regulamentação de EaD a partir das citações de Resoluções, Decretos, Instruções Normativas institucionais. Algo interessante a ser observado é que as IES apresentam conquistas 


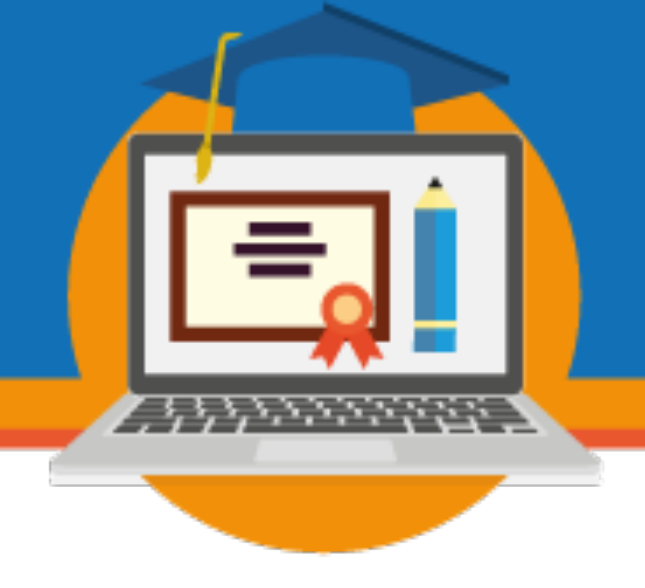

\section{REFERÊNCIAS}

ALONSO, K. M. A expansão do ensino superior no Brasil e a EaD: dinâmicas e lugares. Educ. Soc., Campinas, v. 31, n. 113, p. 1319-1335, out.-dez. 2010. Disponível em: http://www.cedes.unicamp.br. Acesso em: 15 fev. 2020.

BATISTA, E. M.; GOBARA, S. T. As concepções de professores de um curso a distância sobre o papel do fórum on-line. Revista Brasileira de Estudos Pedagógicos, Brasília, v. 87, n. 216, maio/ago. 2006. Disponível em: http://bit.ly/2LIKusN. Acesso em: 26 jul. 2019.

BRASIL. Ministério da Educação. Coordenação de Aperfeiçoamento de Pessoal de Nível Superior (CAPES). Dados abertos. Disponível em: https://dadosabertos.capes.gov.br/. Acesso: 27 dez. 2019

INSTITUTO FEDERAL DE GOIÁS (IFG). Resolução CONSUP/IFG n 40, de 13 de dezembro de 2018. Aprova o Regimento Geral do Instituto Federal de Educação, Ciência e Tecnologia de Goiás. Goiânia, 2018b.

PONTIFÍCIA UNIVERSIDADE CATÓLICA DE GOIÁS. Plano de Desenvolvimento Institucional. Goiânia, PUC Goiás, 2016. (Série Gestão Universitária).

STACHEIRA, C. R. et al. Educação a distância na Universidade Estadual de Goiás - UEG: Trajetória, perspectivas e desafios em processo para consolidação de um paradigma integrador. In: SOUSA, A. H. de et al. Práticas de EaD nas universidades estaduais e municipais do Brasil: cenários, experiências e reflexões. Florianópolis: Ed. UDESC, 2015 . p. 29-37. Disponível em: https://www.uergs.edu.br/upload/arquivos/201607/14155353-livro-praticas-de-ead.pdf.

Acesso em: 01 set. 2019.

III SEMINÁRIO DE EDUCAÇÃO A DISTÂNCIA

Diálogos sobre EaD e uso das TDIC na educação: regulamentação em tempos recentes 3 a 6 de novembro de 2020 - Brasília/DF - Online 


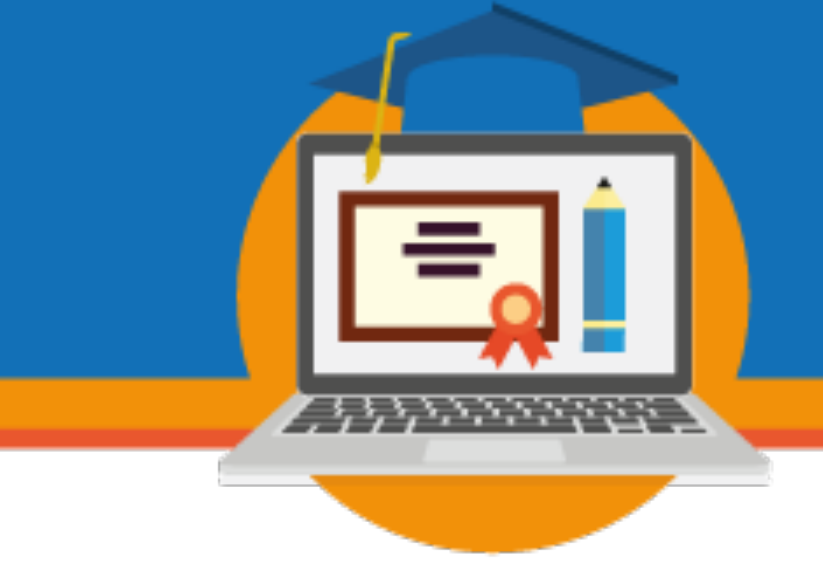

UNIVERSIDADE ESTADUAL DE GOIÁS. Plano de Desenvolvimento Institucional (2010 2019). Anápolis: UEG, 2010. Disponível em: http://www.cdn.ueg.br/arquivos/legislacao/conteudo_compartilhado/944/Res_CsU_2010_009 .pdf. Acesso em: 11 mar. 2019.

VILELA, T. J. V. Institucionalização da educação a distância na Universidade Federal da Grande Dourados (UFGD): Histórico, processos e fases. Dourados: UFGD, 2019. Dissertação (Mestrado). Disponível em: http://files.ufgd.edu.br/arquivos/arquivos/78/MESTRADODOUTORADO-

EDUCACAO/Disserta\%C3\%A7\%C3\%B5es\%20Defendidas/Tania\%20Jucilene $\% 20$ Vieira\%2 0Vilela.pdf. Acesso em: 25 jan. 2020. 